\title{
Arbor
}

\section{La terapia génica ante el nuevo milenio}

Fernando Larcher, Marcela del Río, Marta García, Marta Muñoz, Pedro García Barreno y José L. Jorcano

Arbor CLXVIII, 662 (Febrero 2001), 255-272 pp.

Durante los últimos años está mejorando aceleradamente nuestro conocimiento de las bases genéticas y moleculares de las enfermedades humanas (es decir, qué genes y cadenas de genes toman parte en procesos tales como el desarrollo embrionario, el crecimiento, el envejecimiento, el funcionamiento de los diversos órganos o en enfermedades de alta incidencia como las cardivasculares, la diabetes o el cáncer). Este conocimiento es una consecuencia directa de los avances que durante los últimos 25 años se han venido desarrollando en el campo de la Biología Molecular y Celular que han permitido a los investigadores que trabajan en esta área 1) ser capaces de identificar, aislar, amplificar y modificar genes responsables de múltiples funciones y características animales; 2) poder introducir estos genes, en su forma natural o modificados de maneras predeterminadas, en células y organismos vivos para estudiar sus funciones y efectos.

Se espera que en el futuro inmediato este conocimiento de las bases moleculares de las enfermedades se acelere aún más. Por una parte, la finalización de la secuenciación del genoma humano y la posterior identificación de los genes que lo componen (diferentes investigadores estiman su número entre 60.000 y 100.000) facilitará enormementre el trabajo en este campo. Además, aunque la secuenciación por primera vez del genoma ha sido un proceso costoso tanto temporal como económicamente, la tecnología de secuenciación que se está desarrollando es mucho más potente y se espera que en el futuro será posible secuenciar el genoma de un recién nacido de manera muy rápida y poco gravosa económicamente. Esto permitirá predecir la susceptibilidad individual 
tanto a diversas enfermedades como a los tratamientos disponibles. Por otra parte, la irrupción de nuevas técnicas de alto rendimiento está permitiendo obtener tales cantidades de datos experimentales que éstos sólo pueden ser almacenados y explotados con la ayuda de sofisticados programaas informáticos, lo que ha dado lugar a una nueva disciplina, la Bioinformática. De entre estas tecnologías merecen especial mención la Genómica y la Proteómica, las cuales permiten analizar en un plazo relativamente breve los genes y proteínas de un tejido o tipo celular que alteran su expresión en respuesta a un estímulo o en una situación patológica. Por ejemplo, nos permiten analizar de forma masiva los cambios moleculares que ocurren en las células hepáticas a lo largo de la evolución de un proceso cirrótico o en la respuesta de estas células a diferentes tratamientos. Las compañías farmaceúticas están volcándose en el uso de estos métodos por suponer que permitirán identificar genes clave en el desarrollo de las patologías, lo que abriría la posibilidad de utilizarlos directamente como armas terapeúticas o de diseñar medicamentos que actúen específicamente sobre ellos, con pocos efectos secundarios para el paciente.

Imbricada con todos estos avances está la Terapia Génica: la transferencia de genes a células y tejidos con fines terapeúticos es una consecuencia lógica de ellos y, al mismo tiempo, esta aplicación terapeútica hace todavía más importante la investigación básica sobre las bases moleculares de las enfermedades. Su atractivo radica en que la Terapia Génica posee el potencial de corrección a largo término y puede ser aplicada a enfermedades para las cuales no existen actualmente terapias efectivas. Como se puede ver en la Tabla I, en el momento presente básicamente todos los tipos de enfermedades son candidatos a recibir un «tratamiento genético». Dadas sus diversas características, puede afirmarse que cada tipo de enfermedad requiere una estrategia diseñada a medida. Por ejemplo, la base genética de la enfermedad (monogénica o poligénica/multifactorial) condiciona el tipo de estrategia a seguir.

Las enfermedades monogénicas son enfermedades, generalmente hereditarias, que resultan de la mutación de un solo gen y, en consecuencia, de la pérdida de función de una proteína, como la hemofilia, fibrosis quística, hipercolesterolemia familiar, deficiencia de alfa-1 antitripsina, genodermatosis, etc. En estos casos, la estrategia es muy clara: reintroducir el gen normal en las células afectadas. En algunos casos como la hemofilia, el gen puede ser introducido en tipos celulares o tejidos (por ejemplo, la piel o el músculo) diferentes del usual (el hígado) siempre que su producto, el factor de coagulación, tenga acceso a la circulación 


\section{La terapia génica ante el nuevo milenio}

TABLA 1. Tipos de enfermedades abordadas en el presente por terapia génica

\begin{tabular}{|c||}
\hline HEMOFILIA \\
INMUNODEFICIENCIAS \\
CÁNCER \\
VASCULAR/ANGIOGÉNESIS \\
CARDIACAS \\
SIDA \\
HEPATITIS \\
ENFERMEDADES INFECCIOSAS \\
MUSCULARES \\
ARTRITIS/ARTROSIS \\
NEURONALES \\
DIABETES \\
ANEMIAS \\
GENODERMATOSIS \\
VACUNAS \\
\hline
\end{tabular}

sanguínea que es donde ejerce su acción. En otros, como la fibrosis quística, la introducción del gen debe realizarse específicamente en los tejidos afectados (epitelio pulmonar, gastrointestinal, etc.).

Las enfermedades poligénicas agrupan una gran variedad de trastornos, entre ellos los más comunes (enfermedad coronaria, diabetes, cáncer, SIDA, etc.) en cuya etiología se hallan implicados varios genes. En estos casos, la complejidad genética complica enormemente el problema. En la mayor parte de los casos no conocemos todos los genes implicados ni sus interrelaciones, por lo que no nos podemos plantear corregir la enfermedad, sino tan sólo paliarla, retrasarla o, en el mejor de los casos, cuando es posible, como en el cáncer, destruir las células afectadas. Sin embargo, una de las potenciales ventajas de la Terapia Génica a la hora de diseñar tratamientos contra este tipo de enfermedades es que estos tratamientos pueden ser muy específicos, prácticamente diseñados para cada paciente. Por ejemplo, en el caso del cáncer, cuando un tumor de un determinado tipo llega a su grado más alto de malignidad, tiene mutaciones en varios genes. Estos genes son de diferentes categorías: oncogenes (favorecedores del proceso tumoral), genes supresores de tumores (inhibidores de los tumores), genes relacionados con la apoptosis (regulan la supervivencia celular), genes implicados en el reconocimiento por el sistema inmune (los tumores evaden la vigilancia inmunológica), etc. Aunque estas mutaciones se van acumulando según el tumor progresa en su proceso de malignización, esta acumulación presenta cierta variabilidad, de modo que 
no todos los tumores tienen mutaciones exactamente en los mismos genes en un determinado momento, ni las que tienen en un gen son idénticas. Esto hace que los tumores, incluso los de un mismo tipo, sean genéticamente diferentes $\mathrm{y}$, por lo tanto, su tratamiento podría ser también diferente. Estas discriminaciones tan finas no son posibles con las armas terapeúticas convencionales de que actualmente disponemos, pero serán probablemente posibles en el futuro a través de la Terapia Génica.

\section{Tipos de Terapia Génica}

Teniendo en cuenta cómo se administra el gen terapeútico, se distinguen dos tipos de Terapia Génica:

- In vivo. Usando alguno de los vectores que se describirán más tarde, el gen terapeútico se administra directamente al paciente. Dependiendo del tipo de enfermedad, esta administración es frecuentemente a través del torrente sanguíneo, pero existen otra posibilidades, tales como inyección directa en músculo o en un tumor, spray de inhalación nasal, etc. No todos los vectores son aptos para ser usados de todas estas formas. Por ejemplo, los vectores retrovirales son rápidamente inactivados por el complemento $\mathrm{y}$, por lo tanto, no son útiles para ser inyectados en el torrente sanguíneo; por el contrario, los vectores adenovirales son muy eficientes para ser administrados de esta manera aunque no alcanzan a todos lo órganos con igual eficacia, siendo sus blancos principales el hígado y los pulmones.

Esta es la modalida del futuro ya que en ella los genes terapeúticos se administran de manera parecida a los medicamentos actuales. Sin embargo, estamos todavía lejos de conseguir que funcione adecuadamente, aunque se está trabajando muy activamente en ello.

- Ex vivo. En esta modalidad se le extraen células al paciente, que son puestas en cultivo in vitro y mientras están en esta situación se les introduce el gen terapeútico. Tras comprobar in vitro que los resultados de esta manipulación son los deseados (por ejemplo, que los niveles del producto terapeútico son suficientemente altos o que no se detecta ninguna alteración en las células), las células manipuladas son trasplantadas al paciente. En la Figura 1 se presenta un esquema de este tipo de terapia usando la piel. Aunque más complicada técnicamente, ya que implica el establecimiento de cultivos in vitro y el posterior trasplante de las células, esta modalidad presenta algunas ventajas: se pueden utilizar todos los tipos de vectores existentes; los 

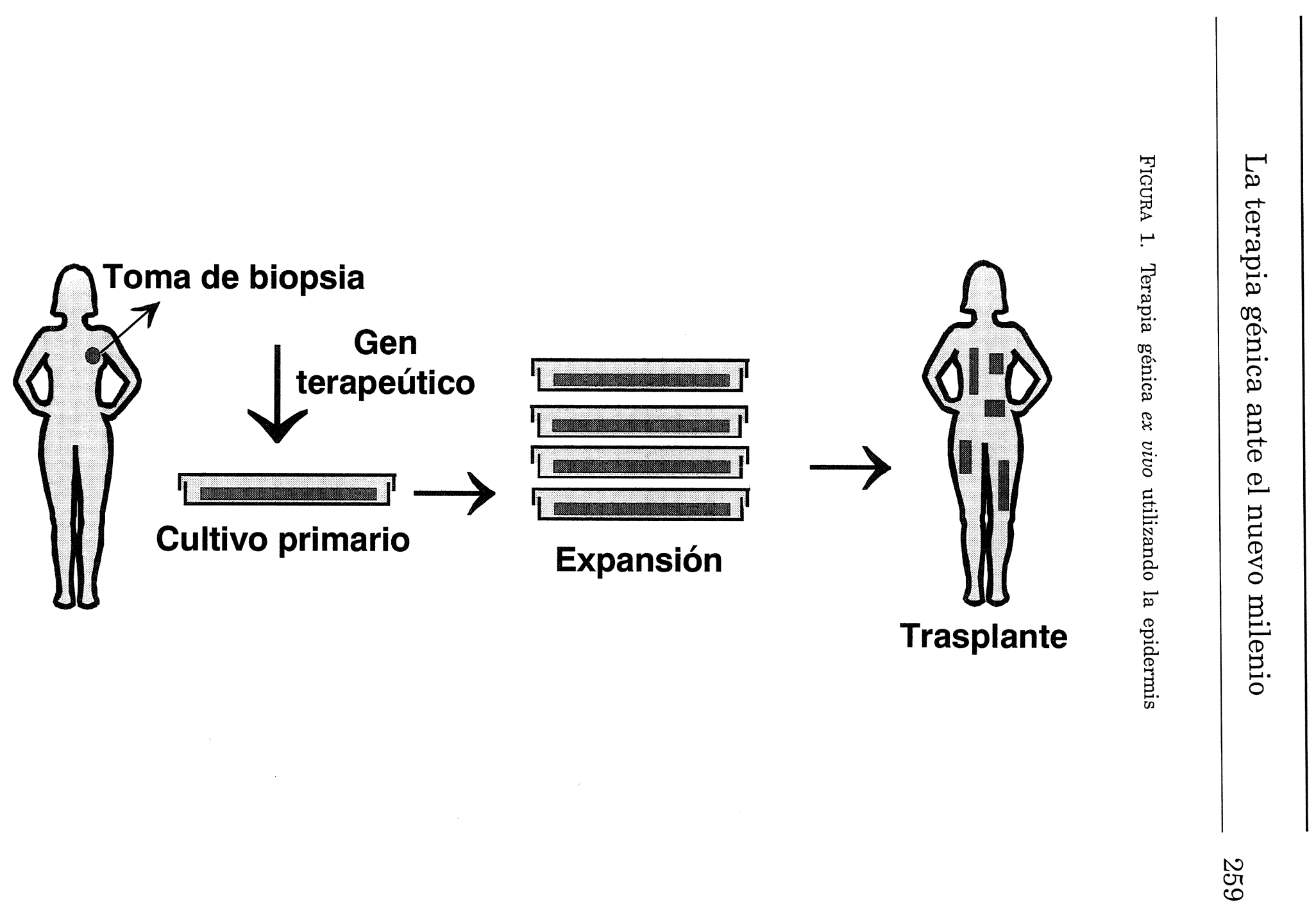
vectores no se introducen directamente en el paciente, con lo que disminuye la toxicidad y sus riesgos asociados; el resultado de la manipulación puede ser estudiado antes del trasplante, incluso pueden seleccionarse con criterios adecuados las células a trasplantar. Todo ésto redunda en una mayor eficacia y seguridad, por lo que una buena parte de los protocolos que en momento presente se están ensayando son de este tipo.

Considerando el tiempo de duración de la actividad del gen terapeútico, hay casos, como por ejemplo en enfermedades monogénicas hereditarias tales como la hemofilia, en que es necesaria una corrección permanente de la enfermedad y es necesario, por lo tanto, conseguir que el gen terapeútico sea funcional durante toda la vida del paciente $\mathrm{o}$, al menos, durante prolongados periodos. Por el contrario, existen otras situaciones, como, por ejemplo, en el caso de tumores, en los que sólo se requiere una terapia transitoria, ya que la actividad del gen terapeútico no es requerida, y a veces no es deseable, más allá del tiempo necesario para llevar a cabo la corrección. Como veremos más adelante, aunque todavía imperfectos, se están desarrollando métodos de introducir los genes terapeúticos en las células a corregir que sean lo suficientemente flexibles para dar respuesta a estas demandas. En este contexto cabe mencionar que todas las correcciones que en el momento presente se están llevando a cabo son de adición, es decir, añadimos a las células una copia del gen terapeútico. Sin embargo, desde el punto de vista de nuestras capacidades de alterar genéticamente las células, podemos llevar a cabo modificaciones genéticas mucho más sofisticadas y precisas. Por ejemplo, haciendo uso de la técnica de la recombinación homóloga en células embrionarias de ratón, somos capaces de sustituir un gen predeterminado o partes de él, de manera muy precisa, sin alterar el resto del genoma y, a partir de estas células, generar ratones que porten esta modificación. Es decir, podríamos hablar de una auténtica cirugía genética. A través de estas técnicas sería posible «operar» un gen mutado y sustituir su región alterada por otra intacta. Desgraciadamente, estas técnicas, conocidas como de sustitución genética, funcionan muy ineficientemente en células humanas somáticas y no son todavía aplicables en Terapia Génica, aunque, por su tremendo potencial, están siendo estudiadas intensamente.

\section{Métodos de transferencia génica}

En estos momentos, quizás el punto crítico de la Terapia Génica resida en nuestra capacidad de mejorar los sistemas existentes de 


\section{La terapia génica ante el nuevo milenio}

transferencia de genes a células: han de ser seguros, eficaces, capaces de funcionar en cualquier tipo de células, tanto si éstas se dividen como si no lo hacen, garantizar la estabilidad de la expresión del gen terapeútico e, idealmente, de actividad controlable en función de las características del problema a tratar. La práctica demostró que estos objetivos son más difíciles de alcanzar que lo que los datos iniciales hacían prever y, por ello, es un campo de intensísima investigación: nuevos vectores y nuevas generaciones de los ya existentes aparecen casi continuamente.

Denominamos vector al vehículo utilizado para transferir material genético a las células diana. El término «transducción» indica la transferencia del gen terapeútico, mediada por el vector, a las células blanco. Los vectores se clasifican en virales o no virales, según deriven de un virus o no. Puesto que los virus de eucariotas, y en particular los que afectan a humanos, han evolucionado para transferir material genético con mayor eficacia a células humanas, los vectores derivados de ellos transducen en general mucho más eficientemente que los vectores no virales y por ello son los más profusamente utilizados en el momento presente. Sin embargo, los vectores no virales presentan menor riesgo patogénico y se pueden producir a gran escala por métodos químicos a modo de fármacos clásicos; estas cualidades les hacen muy atractivos para las compañías farmaceúticas, por lo que también se trabaja activamente en su desrrollo. En la Tabla 2 se muestran los principales tipos de vectores utilizados en terapia génica, sus propiedades, y las limitaciones distintivas de cada vector, que en conjunto determinan sus posibles aplicaciones.

Los retrovirus fueron los primeros virus empleados como vectores de transferencia y siguen siendo los más usados. Tienen la enorme ventaja de que integran su material genético $\mathrm{y}$, por lo tanto, el gen terapeútico que se les ha introducido, en el genoma de las células que infectan, lo que permite su empleo en enfermedades que requieran su expresión a largo plazo. Actualmente, aproximadamente el $60 \%$ de los protocolos clínicos existentes emplean estos vectores. Todos lo virus usados como vectores son patógenos potenciales o reales de los humanos, por lo que hay que modificarlos para convertirlos en «seguros». Para ello, se les quitan los genes responsables de su patogenicidad, que son sustituídos por el gen terapeútico. Dado que el tamaño del genoma de un virus no se puede incrementar, el tamaño del gen o genes que en él se introducen no puede superar al de los genes que se extraen. Este parámetro es una característica importante de cada tipo de vector, ya que limita el tamaño del gen terapeútico (ver Tabla 2); en el caso 
de los retrovirus, este tamaño es de 8 kilobases ( $\mathrm{kb}$ ), adecuado para la mayoría de propósitos.

TABLA 2. Propiedades de los sistemas de transferencia génica más comunes ${ }^{1}$

\begin{tabular}{|c|c|c|c|}
\hline Tipo & Vector & $\begin{array}{l}\text { Duración } \\
\text { de } \\
\text { expresión }\end{array}$ & Características distintivas \\
\hline \multirow{3}{*}{ No viral } & Liposomas & Transitoria & $\begin{array}{l}\text { Es posible su administración repetida y segura; } \\
\text { poco eficiente, expresión transitoria }\end{array}$ \\
\hline & $\begin{array}{l}\text { ADN desnudo } \\
\text { (inyección, pistola de } \\
\text { genes, electroporación) }\end{array}$ & Transitoria & $\begin{array}{l}\text { Fácil de producir, poco eficiente, expresión } \\
\text { transitoria,sin límite de tamaño }\end{array}$ \\
\hline & $\begin{array}{l}\text { Conjugados } \\
\text { moleculares }\end{array}$ & Transitoria & $\begin{array}{l}\text { Diseño flexible, poco eficiente, expresión } \\
\text { transitoria, poco estable in vivo }\end{array}$ \\
\hline \multirow{4}{*}{ Viral } & Retrovirus & Prolongada & $\begin{array}{l}\text { Se integra en el cromosoma de células en } \\
\text { división, poco estable in vivo, admite } 8 \mathrm{~kb} \text { de } \\
\text { ADN exógeno }\end{array}$ \\
\hline & Adenovirus & Transitoria & $\begin{array}{l}\text { Muy eficiente in vivo, se produce en altas } \\
\text { concentraciones, se puede modificar su tropismo } \\
\text { celular, induce una potente respuesta infla- } \\
\text { matoria e inmune, admite } 35 \mathrm{~kb} \text { de ADN exógeno }\end{array}$ \\
\hline & $\begin{array}{l}\text { Virus adeno-asociado } \\
(\mathrm{AAV})\end{array}$ & Prolongada & $\begin{array}{l}\text { No patogénico, escasa capacidad, producción a } \\
\text { gran escala difícil, admite } 5 \mathrm{~kb} \text { de ADN exógeno }\end{array}$ \\
\hline & Lentivirus & Prolongada & $\begin{array}{l}\text { Se integra en el cromosoma de células en } \\
\text { división y fuera de ciclo, sistema de producción } \\
\text { aún no bien establecido, riesgo controvertido }\end{array}$ \\
\hline
\end{tabular}

1 The Journal of Gene Medicine, 1999.

La Figura 2 describe el proceso de generar un retrovirus portador de un gen terapeútico. Los primeros vectores usados se derivaron del virus de la leucemia murina de Moloney. A éste se le extraen los genes Gag, Pol y Env, que codifican por proteínas reguladoras y de la envuelta del virus, y se sustituyen por el gen terapeútico. El vector resultante, si se introduce en células, no puede dar lugar a virus al haber perdido la capacidad de producir las envueltas. En paralelo, se modifica de nuevo el genoma del retrovirus original, al que se le inactiva esta vez el gen $\psi$ (pasa de ser $\psi^{+}$a ser $\psi$ ), que es el responsable de empaquetar el genoma del virus dentro de la envuelta vírica; este virus mutante recibe el nombre inglés de «helper» (auxiliador). Al in- 


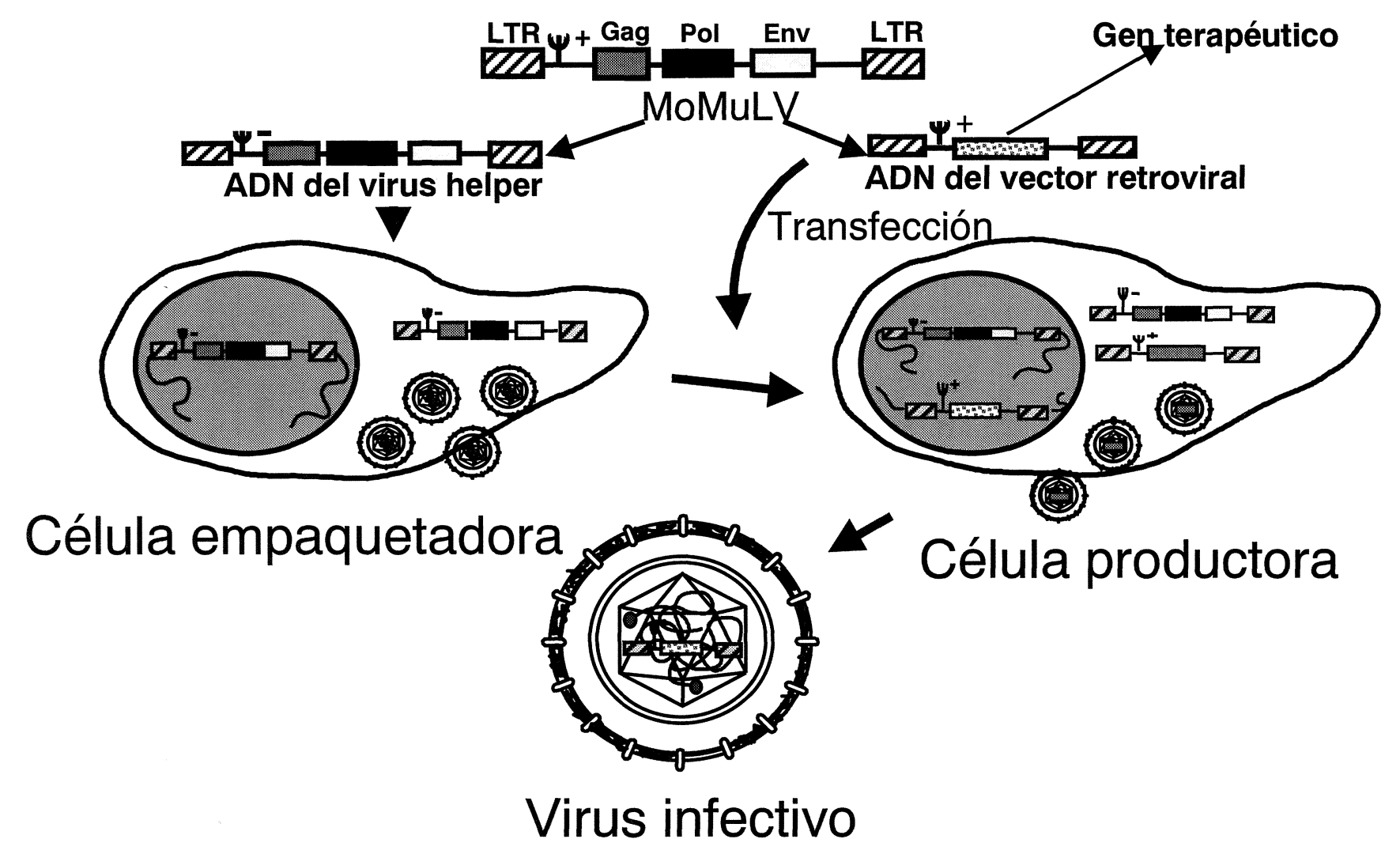


troducirlo en células en cultivo, éstas producirán todos los componentes del virus: envueltas y genomas; pero los genomas $\psi^{-}$no se pueden empaquetar en las cápsidas, que quedan vacías. En estas células, llamadas empaquetadoras, se introduce el ADN del vector con el gen terapeútico. Gracias a la presencia del virus helper, este ADN será copiado repetidamente («replicado») y las copias (que son $\psi^{+}$) serán empaquetadas en las envueltas víricas existentes, dando lugar a virus infectivos, es decir, que pueden ser usados para infectar células e integrar en sus genomas el gen terapeútico. Además de potencialmente terapeúticos, estos virus, en principio, son seguros ya que, por caracer de los genes Gag, Pol y Env, no pueden dar lugar a retrovirus en una célula normal.

Los retrovirus presentan dos problemas. Por una parte, sólo son capaces de transducir células que se dividen activamente. Es el caso de las células humanas cuando se cultivan in vitro, o el de células tumorales. Pero algunos tipos celulares importantes no se dividen, como, por ejemplo, las neuronas. Por otra parte, puesto que el genoma retroviral se integra al azar en el de la célula blanco, puede hacerlo dentro de un gen importante de ésta dando lugar a un fenómeno llamado mutagénesis insercional. Afortunadamente, la probabilidad de que ésto ocurra es pequeña y no ha sido observada nunca en pacientes. Debido a sus características, los protocolos basados en retrovirus son usados en terapias ex vivo. Además, cuando se usan in vivo introducidos, por ejemplo, a través de la sangre, estos vectores son rápidamente inactivados y son difíciles de dirigir hacia el tejido de interés. Estos «defectos» han motivado la continua modificación de los vectores retrovirales, tratando de mejorar sus características, así como el uso de otros tipos de vectores virales.

Los adenovirus humanos del tipo 5, que causan resfriados leves, son una de las alternativas más usadas. Debido a su gran tamaño, permiten transferir regiones de $\mathrm{ADN}$ de hasta $35 \mathrm{~kb}$; son muy eficientes infectando muchos tipos celulares, incluyendo células que no se dividen, tanto in vitro como in vivo y pueden ser producidos a muy altas concentraciones. Sin embargo, también adolecen de defectos. Por no integrar su genoma en el de la célula blanco, en células que se dividen acaban diluyéndose y perdiéndose sus efectos. Por otra parte, generan reacciones inflamatorias e inmunitarias fuertes en el paciente, lo que limita el número de ellos que se puede administrar y, además, hace que se sólo se puedan aplicar una sóla vez al paciente, lo que claramente constituye una seria complicación. Para evitar este problema, se han generado recientemente vectores sin genes virales (los llamados «gutless» 
o «sin tripas») y, aunque la experiencia con ellos es todavía limitada, los resultados existentes parecen indicar que, efectivamente, la respuesta inmune frente a ellos está disminuída.

Otros dos tipos de vectores cuyo uso está ganado muchos adeptos son los derivados de los virus AAV (virus asociado al adenovirus) y de los lentivirus (virus HIV del SIDA). La capacidad de estos vectores de infectar tanto células en división como quiescentes, así como las recientes y continuas mejoras técnicas respecto a su producción y manejo, hacen preveer que serán ampliamente usados en el futuro. Finalmente, otro aspecto en el que se han producido avances significativos es en la capacidad de manipular genéticamente los vectores virales para modificar su envuelta proteica de tal manera que solamente infecten tejidos previamente determinados (es decir, que aunque se diseminen por el torrente sanguíneo, sólo sean capaces de reconocer e infectar células hepáticas o pancreáticas, etc).

A pesar de que, a la vista de lo expuesto, parece probable que en el futuro no existirá un vector «universal» sino un conjunto de vectores adecuados para ser usados en diferentes situaciones y que, claramente, los vectores existentes tienen que ser mejorados en diferentes aspectos, los continuos avances que se producen permiten ser optimistas de cara a la obtención de vectores suficientemente eficaces, estables, regulables, seguros y flexibles.

\section{Resultados clínicos}

La Terapia Génica es todavía un tratamiento experimental. Su aplicación está restringida a protocolos de ensayos clínicos realizados en centros médicos cualificados, bajo el riguroso control de diversas agencias gubernamentales y comités institucionales. Se ha difundido la opinión de que, a pesar de las altas expectativas iniciales, la Terapia Génica cuenta con pocos éxitos en su haber. A la hora de hacer estas afirmaciones hay que tener en cuenta varios hechos. Por una parte, como siempre ocurre con nuevos fármacos, una buena parte de los ensayos clínicos llevados a cabo hasta la fecha son de fase I/II, diseñados para determinar la factibilidad/toxicidad del ensayo casi más que su potencial terapeútico. En estos ensayos los pacientes involucrados son pocos y, casi siempre, se hallan en fase avanzada o terminal de su enfermedad, habiendo sido tratados previamente con diferentes drogas. La falta de experiencia hace que las dosis de vectores y los métodos de administración sean necesariamente empíricos y no siempre los adecuados. Todo ésto hace 
difícil extraer conclusiones acerca de las potencialidades terapeúticas reales de los métodos empleados. Por otra parte, y ésto es lo realmente importante, datos muy recientes indican que se está llegando a correcciones reales en pacientes. Como era de esperar, dos de las enfermedades en las que se están obteniendo estos resultados son monogénicas: hemofilia y ADA. En la primera, los valores estables del factor IX de coagulación obtenidos, aunque todavía no curativos, empiezan a permitir que los pacientes vayan espaciando las inyecciones del factor. En el caso del ADA, se ha comunicado la obtención de concentraciones terapeúticas en sangre durante más de un año. Otro caso donde se han logrado resultados inesperadamente favorables, por tratarse de una situación más compleja, es el tratamiento post-infarto del músculo cardiaco con VEGF (factor de crecimiento del endotelio vascular). Este tratamiento permite una rápida revascularización de la zona dañada y parece mejorar la recuperación del paciente.

Además, los ensayos clínicos están permitiendo llegar a conclusiones globales importantes. Por ejemplo, se está acumulando información respecto a múltiples aspectos relacionados con la biología y la farmacología de la transferencia de genes en el contexto de diversas enfermedades. A pesar de que recientemente se ha informado de algunas muertes de pacientes, las estrategias utilizadas parecen poco tóxicas, sobre todo en el caso de los vectores retrovirales, cuya capacidad real de producir mutagénesis insercional era importante evaluar. Finalmente, los ensayos clínicos han puesto de manifiesto que, si bien la transferencia de genes es posible, su eficacia presente tiene que ser mejorada y a pesar de las desfavorables condiciones de estos ensayos, algunos resultados fueron alentadores. Estas observaciones, a su vez, están sirviendo para dirigir las nuevas investigaciones de laboratorio, encaminadas a superar los problemas detectados.

El primer ensayo clínico de transferencia génica aprobado en EEUU se realizó en 1989 y no tenía una finalidad terapeútica. El siguiente ensayo, esta vez terapéutico, comenzó en 1990 en una paciente con síndrome de inmunodeficiencia combinada, y consistió en la infusión de linfocitos $\mathrm{T}$ modificados con la enzima deaminasa de adenosina (ADA). Desde entonces, más de 3.000 pacientes han recibido terapia génica en todo el mundo. Los Institutos Nacionales de la Salud de EE.UU (NIH), el organismo que controla y aprueba los ensayos clínicos, tenía en el mes de agosto de 2.000 registrados 431 protocolos, de los que el $91 \%$ eran de su propio país (Tabla 3). Aunque estos datos pueden adolecer de una cierta falta de información de los NIH respecto a lo que ocurre en otros países, ciertamente demuestran la enorme ventaja 


\section{La terapia génica ante el nuevo milenio}

que en este campo, de gran importancia para la medicina, y por tanto para la economía, del futuro llevan los estadounidenses al resto del mundo. Esto es debido, entre otros, a dos factores: 1) En esta disciplina es absolutamente necesario integrar investigadores básicos (que poseen y desarrollan los métodos) con investigadores clínicos (que entienden las enfermedades y pueden tratar a pacientes). Mientras que los norteamericanos han llevado a cabo esta integración de una forma bastante satisfactoria, ésta es muy difícil de conseguir en otros países y, en particular, en el nuestro. 2) En un campo con un enorme potencial futuro pero todavía de claro riesgo, es necesario conseguir una adecuada financiación para desarrollar los protocolos y llevar a cabo ensayos clínicos, que son muy costosos. El interés de las empresas estadounidenses por este campo, la capacidad de este país para aportar capital-riesgo y su facilidad para crear empresas «start-up», en las que se integran los investigadores que han llevado a cabo los desarrollos técnicos, son cualidades que nuestro país tiene que imitar de modo inmediato si no quiere perder sus oportunidades de futuro en este campo de tan alto potencial en el que, por otra parte, dispone de investigadores que están realizando una investigación altamente competitiva.

TABLA 3. N. ${ }^{\circ}$ de ensayos presentados hasta agosto de $2.000^{*}$

\begin{tabular}{|l|c|c|}
\hline & Número & $\%$ \\
\hline EE.UU. & 393 & 91 \\
\hline RESTO DEL MUNDO & 38 & 9 \\
\hline TOTAL & 431 & \\
\hline
\end{tabular}

* Datos de Human Gene Therapy.

A pesar de los por algunos considerados progresos demasiado parciales, el interés por la Terapia Génica aumentó continuament a lo largo de la década de los 90 , como lo demustra el constante incremento en el número de ensayos clínicos presentados a los NIH para su aprobación (Tabla 4). Como se muestra en la Tabla 5, ya han pasado la etapa de experimentación básica y han llegado al estado de ensayo clínico protocolos diseñados para tratar una gran variedad de enfermedades. Como se documenta en esta Tabla, más de la mitad de los ensayos clínicos van dirigidos al tratamiento del cáncer. Dada la complejidad de esta enfermedad poligénica y la mutiplicidad de tipos de 
TABLA 4.

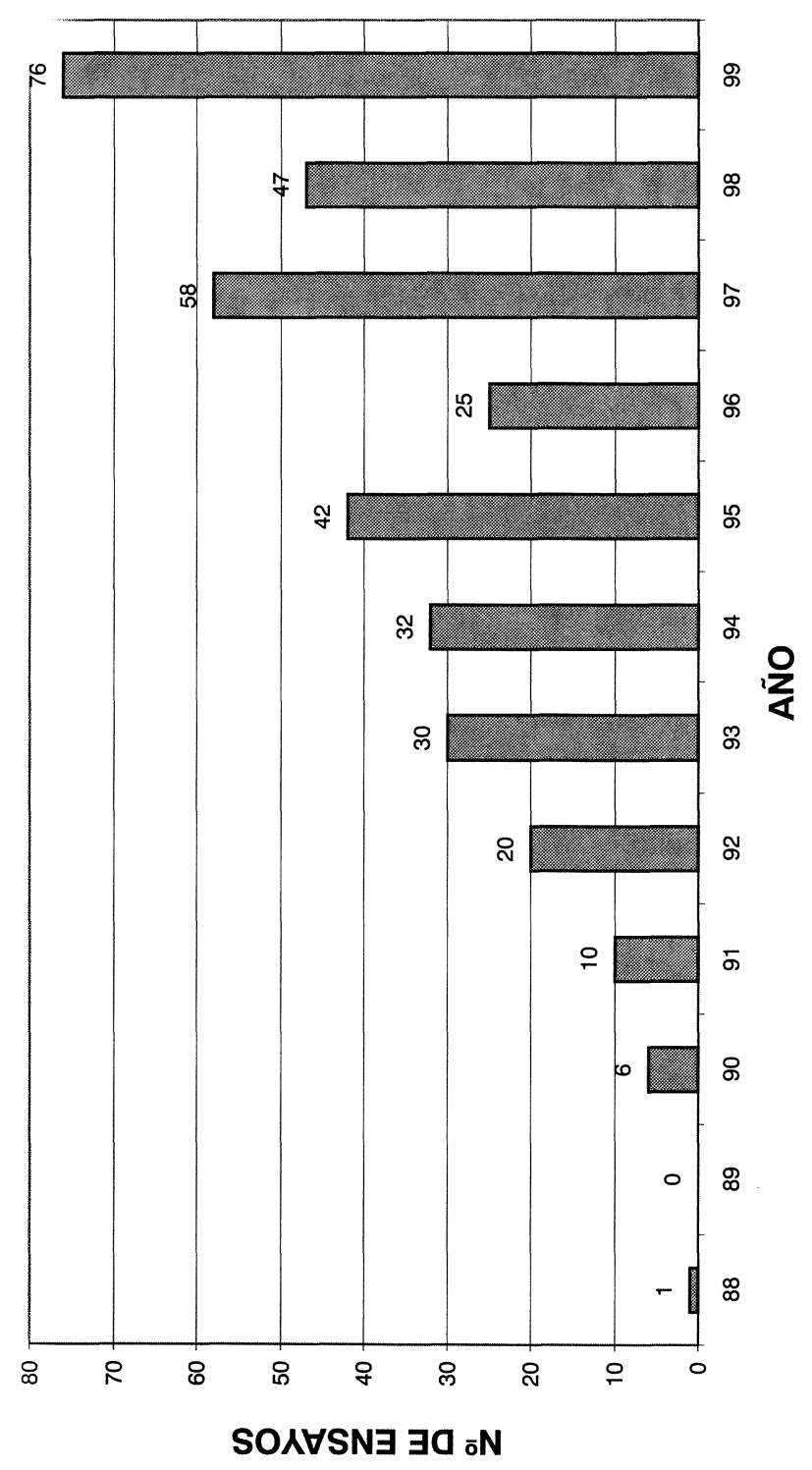




\section{La terapia génica ante el nuevo milenio}

cáncer, con muy poca relación entre sí tanto en lo que se refiere a sus componentes genéticos como a la evolucion de la enfermedad, se están desarrollando diversas estrategias anticáncer tales como la compensación de mutaciones, la terapia antiangiogénica, la quimioterapia molecular y la potenciación genética del sistema inmune.

TABla 5. N. ${ }^{\circ}$ de ensayos presentados hasta agosto 2.000 por tipos*

\begin{tabular}{||l|c|c||}
\hline \multicolumn{1}{|c|}{ Tipo } & N. $^{\circ}$ & $\%$ \\
\hline CANCER & $271(70)^{* * *}$ & $64(16)^{* * *}$ \\
\hline SIDA & 33 & 9 \\
\hline CARDIOVASCULAR & 28 & 7 \\
\hline FIBROSIS CISTICA & 25 & 6 \\
\hline INMUNODEFICIENCIAS & 7 & 2 \\
\hline HEMOFILIA & 6 & 1 \\
\hline METABOLICAS & 6 & $<1$ \\
\hline ANEMIAS & 3 & $<1$ \\
\hline DISTROFIAS MUSCULARES & 3 & $<1$ \\
\hline ARTRITIS & 2 & $<1$ \\
\hline NEURODEGENERATIVAS & 2 & 5 \\
\hline OTRAS & 23 & $<$ \\
\hline
\end{tabular}

* Datos de Human Gene Therapy

** Inmunoterapia.

Mediante la compensación de mutaciones se trata de corregir las alteraciones genéticas encontradas en los diferentes tipos de tumores, las cuales están implicadas en la aparición, progresión y metástasis tumoral; el gen p53 ha sido utilizado en la mayoría de este tipo de ensayos. En la terapia antiangiogénica se trata de evitar la contribución al crecimiento tumoral de los vasos sanguíneos que lo alimentan, sin los que el tumor no puede crecer ni hacer metástasis. La quimioterapia molecular busca inducir un efecto citotóxico selectivo en la célula tumoral o en las células del estroma. El paradigma es la administración selectiva del gen de la enzima timidina quinasa (TK) seguido de la administración 
sistémica de la prodroga ganciclovir. En las células que expresan TK el ganciclovir es transformado en un metabolito tóxico. Para asegurar la selectividad necesaria de dicho efecto es necesario controlar la entrega del gen tóxico, o su expresión, limitándola al tejido tumoral. Alternativamente, la quimioterapia molecular intenta aumentar la sensibilidad del tumor a quimioterapia o radioterapia convencionales. Para ello se transfieren genes cuyos productos actúan sobre los mecanismos de acción de las drogas citotóxicas o de la radiación, sensibilizando así a la célula receptora. Otra estrategia consiste en transferir genes que protegen a la médula ósea y otros tejidos normales de los efectos tóxicos de drogas citotóxicas convencionales, como el gen MDR-1 de la resistencia a múltiples drogas. Esto permite la administración de mayores dosis sin alcanzar niveles intolerables de mielosupresión. Finalmente, con la potenciación genética del sistema inmune se propone inmunizar el paciente contra antígenos asociados al tumor mediante la transferencia de una variedad de genes, incluyendo los propios antígenos y genes que activan el sistema inmune. Con este propósito se han modificado genéticamente tanto células tumorales como células del sistema inmune con moléculas estimuladoras, tales como interleuquinas. A pesar de todos estos esfuerzos, y como se preveía debido a su complejidad, el cáncer está revelándose como una enfermedad difícil de corregir y los progresos han sido modestos.

\section{El futuro de la Terapia Génica}

Las bases conceptuales de la terapia génica pueden considerarse como consolidadas. Durante la pasada década, la seguridad de la transferencia de genes al ser humano, aunque no absoluta, se ha confirmado repetidamente como adecuada y mejorable en cuanto se amplíe la experiencia. Quedan ahora, no obstante, problemas serios que resolver para lograr que la terapia génica sea eficaz, práctica, ampliamente disponible y económicamente asequible. El mayor de todos ellos es desarrollar la tecnología que permita una transferencia de genes eficiente y dirigida in vivo al tejido diana. Con los avances en la tecnología de vectores, es posible anticipar que los resultados prometedores observados tantas veces en los estudios preclínicos se obtendrán también en la clínica y permitirán mejorar el tratamiento de multitud de enfermedades que se acompañan actualmente de alta morbimortalidad. Ello requerirá unos años de intensa investigación conjunta entre laboratorios y hospitales. 


\section{La terapia génica ante el nuevo milenio}

\section{Las promesas de la Medicina}

A la vista de lo descrito acerca de la Terapia Génica, de los avances que están produciéndose acerca del entendimiento de las bases moleculares de las enfermedades y de los que se esperan debidos a la secuenciación del genoma humano y a la aplicación de las tecnologías de la genómica y proteómica, estamos asistiendo a una revolución en el concepto de la Medicina, tanto en sus aspectos diagnósticos como en los terapeúticos. Uno de los aspectos que ciertamente veremos emerger es el de Medicina «a la carta» o individualizada, es decir, específica para cada enfermedad de cada paciente (véase la Figura 3):

Figura 3. La medicina del futuro: Previsión-diagnóstico-tratamiento «a la carta»

* Predicción de sensibilidad genética a enfermedades.

Análisis de las características moleculares de la enfermedad.

(Diagnóstico Molecular)

* Predicción de sensibilidad/resistencia a tratamiento en función de las características del paciente y de la enfermedad.

* Diseño de una terapia específica en función de los datos anteriores.

* Ensayo «in vitro» o en modelos animales «humanizados» de la terapia.

* Producción de tejidos y órganos a partir de células stem (madre)

embrionarias o adultas.

* Xenotrasplantes.

La posibilidad de secuenciar el genoma de un recién nacido nos permitirá predecir su grado de predisposición a un número creciente de enfermedades (por ejemplo, analizando si porta mutaciones en genes supresores o moduladores de tumores) e, incluso, predecir su respuesta a determinadas drogas $\mathrm{y}$, por lo tanto, la eficacia de los tratamientos que las incluyan. Por otro lado, será posible determinar qué genes, y en qué grado, están implicados en una enfermedad concreta (por ejemplo, si padece un cáncer de un tipo determinado, qué oncogenes, genes supresores, genes de apoptosis, etc. portan mutaciones y cuales son éstas, o cuales de estos genes presentan una expresión alterada). Con todos estos datos, será posible diseñar una terapia individualizada, potencialmente la más eficaz y con menos efectos secundarios para ese paciente. Además, existirán ensayos «in vitro» (por ejemplo, cultivos de las células afectadas del paciente, tumorales en caso de tratarse 
de un tumor) o en modelos de animales «humanizados» (es decir, portadores de células del paciente) en los cuales evaluar la eficacia de las terapias diseñadas antes de tratar al propio paciente.

Desde el punto de vista terapeútico, también conviene señalar la emergencia de nuevas posibilidades hace poco impensables. Por una parte, la recientemente puesta de manifiesto, y ampliamente debatida en los medios de comunicación, capacidad de llegar a producir tejidos (y, en un futuro más lejano, órganos) a partir de células «stem» pluripotentes obtenidas de embriones o tejidos adultos, abre una prometedora vía para abordar enfermedades actualmente incurables, como las neurodegenerativas o la diabetes, que tanto impacto tienen en nuestra sociedad. Por otra parte, la muy recientemente anunciada capacidad de clonar cerdos, los cuales podrían estar modificados genéticamente de tal manera que sus órganos no fueran rechazados por los humanos, ha vuelto a poner sobre el tapete la posibilidad de los xenotrasplantes. Aunque muchos y muy importantes aspectos de estas posibilidades (por ejemplo, la bioseguridad de los xenotrasplantes, es decir, que no pasen virus porcinos a humanos que den lugar a enfermedades difíciles de controlar, como ocurrió con el SIDA), el futuro que se empieza a entrever es altamente esperanzador pero, si queremos que nuestro país tenga un papel razonablemente protagonista en él, representa un desafío a nuestros investigadores jóvenes, políticos, empresarios y médicos. En concreto, urge que estos últimos sean conscientes de los cambios que se avecinan, entiendan sus bases científicas y tecnológicas y comprendan que en los hospitales tiene que haber una activa investigación desarrollada por equipos formados por investigadores básicos y clínicos. 